\title{
SEM Analysis of Composite Cellulose Acetate Membranes for Separation Operations
}

\author{
L.P. Terrazas-Bandala*, LA. Manjarrez-Nevárez**, A. Duarte-Möller*, M.L. Ballinas- \\ Casarrubias**, G. González-Sánchez* \\ * Advanced Materials Research Center (CIMAV) Miguel de Cervantes 120 Compl. Ind. Chih. \\ 31109, Chihuahua, Chihuahua, MEXICO. \\ ** Chemistry Sciences School, Universidad Autónoma de Chihuahua, Circuito Universitario S/N, \\ Chihuahua, Chihuahua, MEXICO. \\ piroshka.terrazas@cimav.edu.mx
}

\section{INTRODUCTION}

Polymeric composite membranes are used widely in the separation science field. Nowadays their mechanical properties could be superior to the traditional ones. Their resistance to pressure could be higher such as its total performance in membrane operations. Recently [1] composite polysulfone membranes have been used to separate oligosaccharides from an aqueous mixture. Addition of activated carbon to polymeric material really modified bulk properties, altering pore distribution, macrovoid presence and mechanical properties [2].

Present studies demonstrate morphological variations on the development of cellulose acetate composite membranes adding activated carbon in order to be used in driven pressure membrane process.

\section{OBJECTIVE}

Study the correlation among morphological changes in the structure of cellulose acetate membranes by the addition of activated carbon using Scanning Electron Microscopy (SEM).

\section{METHODOLOGY}

Membranes were synthesized using cellulose fibers acetylated by the procedure published elsewhere [3], and commercial activated carbon (LQ, $\left.1280 \mathrm{~m}^{2} / \mathrm{g}\right)$. Carbon was meshed with a mortar and sieved to obtain particles in the range of $53-74 \mu \mathrm{m}$. Synthesis was performed by evaporation method [4] with controlled temperature and humidity $\left(30^{\circ} \mathrm{C}\right.$ and $40 \%$ relative humidity in a chamber Shell Lab 9000). Membranes were cleaned in an Ultrasonic bath (Branson-2510) and treated further in a covering system (Denton Desk-II Gatan). The microscopic analysis was performed at $15 \mathrm{~V}$ in a Scanning Electron Microscope (JEOL, JSM 5800-LV).

\section{RESULTS}

Acetylated cellulose membrane without activated carbon is shown in Fig. 1. Analysis was performed in the SEM conditions described previously. As it can be seen this material is dense and it does not show any appreciable pore in its surface, as it was expected in commonly used reverse osmosis membranes [5].Composite membrane is shown in Fig. 2. As it can be observed, addition of activated carbon $(1 \%)$ produces a symmetric membrane with homogenous pore distribution. A consequence of this phenomenon is that composite material can handle the same flow with less pressure gradient. Next step will be to test the ability of the membranes to remove ions from water.

These results demonstrate the differences among these materials and the high utility of SEM as a powerful tool in structural analysis. [6]. 
References

[1] Ballinas, L. et al. Polymer carbon composite membranes for oligosaccharide separation. Carbon. Oviedo (ESP - ESPAÑA) (2003) ISBN 84- 607-8305-7.

[2] Ballinas, L. et al. Factors influencing activated carbon-polymeric composite membrane structure and performance. Journal of Physics and Chemistry of solids. (2004). Vol 65 (633).

[3] Kogakwsha, Ltd. Unit Processes in Organic Synthesis. Fifth edition. McGraw Hill. (1958).

[4] Mulder, M. The use of membrane processes in environmental problems, in: Membrane Processes in Separation and Purification, Kluwer Academic Publishers, Dordrecht, The Netherlands.(1994) (229).

[5] M. Cheryan: Ultrafiltration Handbook, (1986).

[6] This research was supported by CONACyT México project number J44189-Q, and under PROMEP program for research. The aid of Dra. Hilda E. Esparza Poce (CIMAV) and Q.I. Gabriela Muñiz (UACH) is gratefully acknowledged.

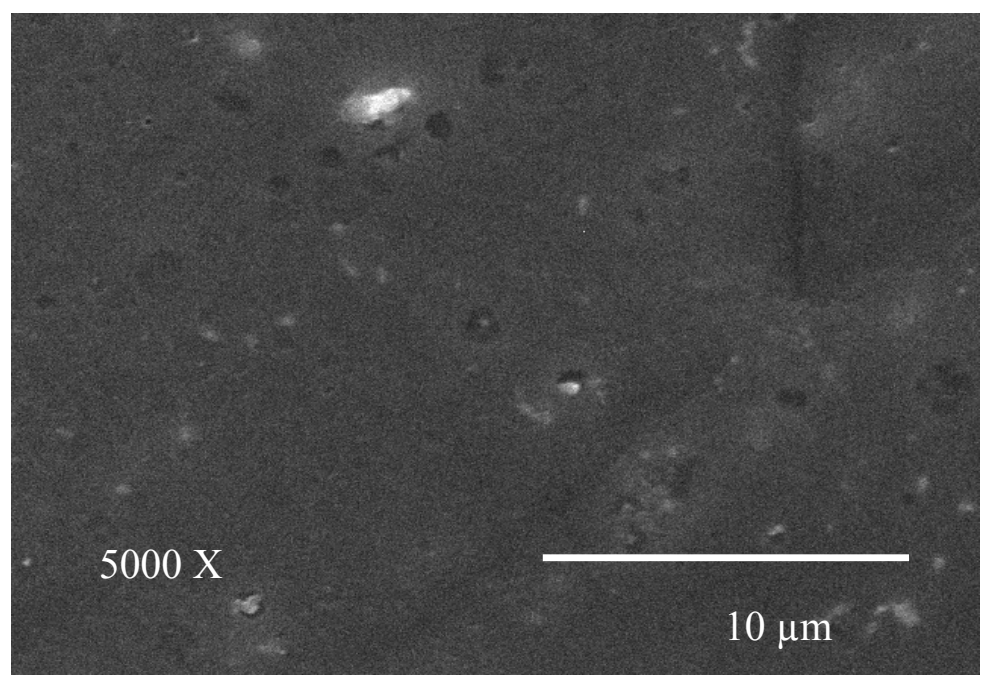

Figure 1. SEM photograph of acetylated cellulose membrane. 5000X.

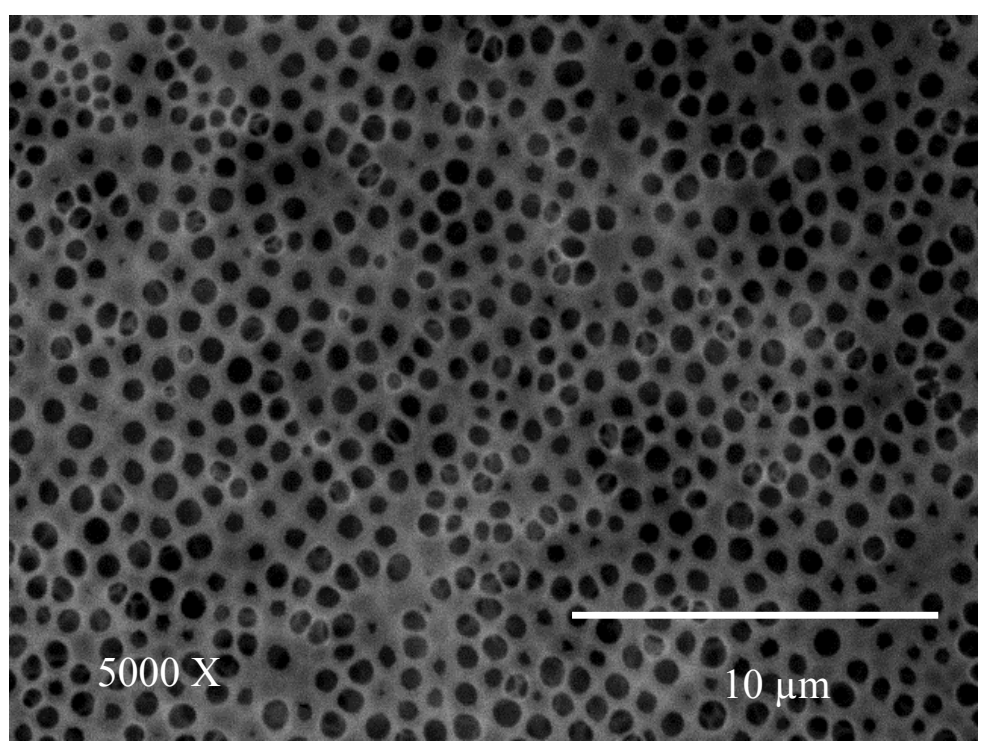

Figure 2. SEM photograph of composite acetylated cellulose membrane. 5000X. 